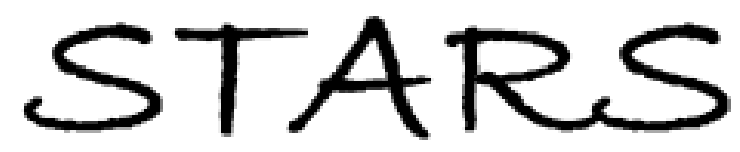

University of Central Florida

STARS

$1-1-2011$

\title{
Structural Dynamics of Organizations during the Evolution of Interorganizational Networks in Disaster Response
}

Alireza Abbasi

Naim Kapucu

University of Central Florida

Find similar works at: https://stars.library.ucf.edu/facultybib2010 University of Central Florida Libraries http://library.ucf.edu

This Article is brought to you for free and open access by the Faculty Bibliography at STARS. It has been accepted for inclusion in Faculty Bibliography 2010 s by an authorized administrator of STARS. For more information, please contact STARS@ucf.edu.

\section{Recommended Citation}

Abbasi, Alireza and Kapucu, Naim, "Structural Dynamics of Organizations during the Evolution of Interorganizational Networks in Disaster Response" (2011). Faculty Bibliography 2010s. 2182.

https://stars.library.ucf.edu/facultybib2010/2182

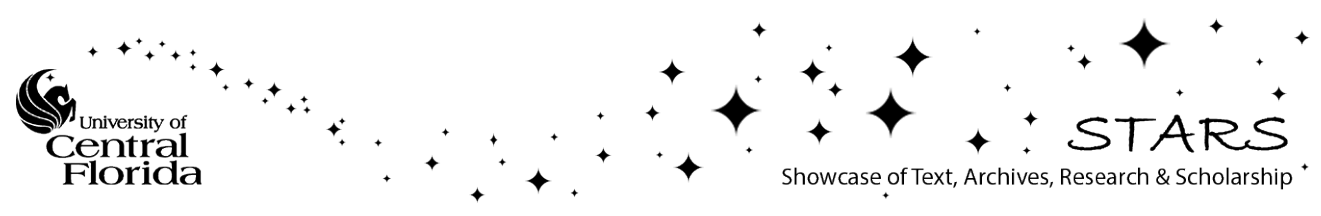




\title{
Journal of Homeland Security and Emergency Management
}

Volume 9, Issue 1

2012

Article 23

\section{Structural Dynamics of Organizations during the Evolution of Interorganizational Networks in Disaster Response}

\author{
Alireza Abbasi, University of Sydney \\ Naim Kapucu, University of Central Florida
}

Recommended Citation:

Abbasi, Alireza and Kapucu, Naim (2012) "Structural Dynamics of Organizations during the Evolution of Interorganizational Networks in Disaster Response," Journal of Homeland Security and Emergency Management: Vol. 9: Iss. 1, Article 23.

DOI: $10.1515 / 1547-7355.1975$

(C)2012 De Gruyter. All rights reserved. 


\title{
Structural Dynamics of Organizations during the Evolution of Interorganizational Networks in Disaster Response
}

\author{
Alireza Abbasi and Naim Kapucu
}

\begin{abstract}
This study analyzes the evolution of interorganizational response networks over time. The study aims to investigate an organization's position and role as a result of the dynamic changes that occur through the evolution of interorganizational response networks. Social network analysis measures are applied in order to evaluate not only network structure and specifications but also an organizations focal structure and role changes over time. Using Hurricane Charley's coordination data of the activities of several organizations involved in the response process over time, the study evaluates networks and the organizations' network structural changes over a period of time. The results show that analyzing static networks does not reflect how the network evolves and how different organizations change their role as the incident emerges. This study takes these criticisms into consideration and adds time dimension to the analysis of response networks. It is the first step in investigating the emerging structure of interorganizational response dynamics during emerging disasters and its effect on improving coordination output. In addition, the study proposes indicators for identifying real, lead or coordinating organizations in interorganizational networks.
\end{abstract}

KEYWORDS: structural dynamics, network evolution, interorganizational networks, disaster response, coordination network, organizational change, network position, emergency response management, network analysis 


\section{Introduction}

Analyzing the relations between organizations has been a major concern of organization theorists for a long time and the units of study have shifted from the dyad to the organization set and then to the network (Provan \& Milward, 1995). Resource dependency and information exchange are important aspects of organizational relationships. Therefore, organizations make strategic choices to form or become part of a cooperative network of other organizations (Uzzi, 1994).

The effective development and operation of interorganizational networks is essential in protecting human lives and property as well as infrastructure damage during disasters (Kapucu \& Ozerdem, 2011). On the other hand, worldwide losses from disasters related to natural hazards have risen dramatically (Munich Re Group, 2005; Swiss Reinsurance Company, 2006) and this trend is growing due to human-induced climate change (Crompton \& McAneney, 2008), which is also expected to grow exponentially in the future (Kapucu \& Ozerdem, 2011).

During a disaster, the situation becomes more complex because of increasing interactions and interdependency among actors (e.g., individual people and organizations). As a result, the need for coordination increases in order to achieve a common goal. Therefore, forming cooperative information exchanges in order to respond to disasters effectively and efficiently is essential for participating (involved) organizations. Both exogenous (e.g., environmental parameters) and endogenous (e.g., formation of links among actors, frequency of interactions, limited capacity of actors) factors, and the resulting structure of interactions among actors (e.g., interorganizational networks) change during the response phase of a disaster.

Poor coordination is a fundamental problem during emergency response, and is primarily due to (i) a lack of efficient communication between organizations, (ii) a lack of up-to-date and relevant information circulation through the emergency response network, and (iii) insufficient access to data and action plans (Hossain \& Kuti, 2010; Van Borkulo, Scholten, Zllatanova, \& van den Brink, 2005).

Therefore, a deep understanding of interorganizational response network structures and the process of locating information flow and exchange is essential in optimizing response networks. This helps emergency managers and policy makers in making better informed decisions. However, reliable data, tools and measures are missing to evaluate the efficiency of interorganizational response networks in the rapidly evolving and changing environment of disasters. This study is the first step in investigating the evolving structure of interorganizational coordination dynamics during disaster response operations and its effect on improving coordination output. 
The study applies network analysis for evaluating the response network's topology and structural change which occurs as a result of the dynamic changes present in disaster response. Network analysis has shown to be applicable to emergency management research as a theoretical lens and analytical tool for discovering the patterns of communications and its dynamics in crisis situations (Abbasi et al., 2010; Durland \& Fredericks, 2002; Hamra et al., in press; Kapucu et al., 2010; Kilduff \& Tsai, 2003; Mandell \& Keast, 2007; Provan et al., 2005; Varda et al., 2009). Thus, it helps us to investigate how interorganizational response networks change during a disaster. This can lead to improving interorganizational coordination and thus enhancing emergency management effectiveness.

The study specifically examines the following research questions: How does an organization's position change through the emergence of interorganizational coordination networks during response to disasters? How can organizations, which play a key coordination role in interorganizational response networks during and after a disaster, be identified?

The 2004 Florida Hurricanes, as one of the greatest natural disasters in American History (Varda et al., 2009), provide a good opportunity to test these research questions. This research's focus is centered on Hurricane Charley's coordination (cooperation) network. The data was collected from a content analysis of government documents, newspaper reports and interviews which has been used in other recent studies exploring the aforementioned phenomenon (Kapucu et al., 2010). This study contributes to emergency management literature by investigating the dynamics of interorganizational response networks for the first time.

The paper is organized as follows: Section 2 provides a review of the existing literature in the context of coordination theory, emergency management and aspects of interorganizational coordination in disaster management studies followed by a brief presentation of social network analysis concepts and measures. In the following Section, an overview of data collection together with the methods used for data analysis is described. In Section 4, the analysis and results are described. Lastly, the paper concludes with a discussion highlighting the contributions and implications of this study on research and practice.

\section{Literature Review}

\subsection{Interorganizational Coordination}

The study of coordination attracts attention from many different disciplines and there is a considerable body of knowledge to be found in the fields of organization theory, management science, computer science, economics and psychology. 
Malone (1988) suggested that it is important to articulate what is meant by coordination as a theory. The aim was to find how the activities of separate actors can be coordinated. It was noted that "good coordination is nearly invisible, and we sometimes notice coordination most clearly when it is lacking" (Malone \& Crowston, 1990, p. 2). Coordination is defined as "the additional information processing performed when multiple connected actors pursue goals that a single actor pursuing the same goals would not perform" (Malone, 1988, p. 5) or "managing the dependencies between activities" (Malone \& Crowston, 1994).

Coordination can be regarded as one of the elements associated with disaster management processes (Kapucu, 2012). McEntire (2002) studied the March 2000 tornadoes in Ft. Worth, Texas, and suggested that the major factors to facilitate coordination are program acceptance, preparedness activities, networking, technology and so on and the factors which hinder it are lack of information, block access, language barriers, etc (Drabek, 2006).

Dynes and Aguirre (1979) highlighted two different types of coordination in organizations: coordination by plan and by feedback. The pre-established planned programs and activities directing and standardizing the functioning of organizations are considered as coordination by plan. This kind of coordination is vastly used for traditional emergency organizations (e.g., police and fire agencies). On the other hand, coordination by feedback is about learning processes and sharing new information in order to facilitate the mutual adjustment of different parties. When there is a large gap in status and power within an organization, more emphasis is on coordination by plan. More emphasis is placed on coordination by feedback in situations where organizational structure is so diverse and/or high that uncertainty exists in the organizational environment (Dynes \& Aguirre, 1979). Coordination by plan reflects a mechanism usually applied in emergency management, the use of a coordinator to control and manage individuals and organizations involved in the response network.

Given that emergency events are frequently dynamic, coordination by plan is usually less optimal and coordination by feedback can be seen as more desirable. In general, in extreme events, the rate of communication elevates and results in creating conditions where organizational structures need to move in the direction of coordination by feedback, to exchange new information, and away from coordination by plan (Dynes \& Aguirre, 1979). However, it can be argued that better performance in managing emergencies would require the use of a mix of both types of coordination.

\subsection{Emergency Management and Interorganizational Networks}

During emergency and disaster situations individuals from different agencies cooperate to properly respond to the incident collectively. Inevitably participants need to interact, communicate and cooperate with each other through the use of

Published by De Gruyter, 2012 
sharing information and experience, reporting and briefings, requesting resources and so on. Therefore, coordination network shapes, including agencies or participants from different organizations or agencies as actors and their communication (interaction), represent the links or ties among actors in order to respond to the emergency.

When a disaster occurs, organizations learn from one another and perform at levels that lie beyond the capacity of the individual organizations acting alone. As emergency response and management increasingly rely on interorganizational response to disasters (Corbacioglu \& Kapucu, 2006; Kapucu, 2006, 2012; Moynihan, 2006; Moynihan, 2005), research on how organizations learn in the face of repeated disasters takes on heightened importance (Kapucu et al., 2010). "Disasters produce unique combinations of choices, actions, and reasoning that cannot be predicted. This perspective better represents the complexity of disaster situations and the problematic nature of post-event evaluations" (Kapucu et al., 2010).

The coordination of emergency response is challenging because it evolves out of the urgent needs of an emergency situation (e.g., great uncertainty; sudden and unexpected events; the risk of possible mass casualty; high amounts of time pressure and urgency; severe resource shortages; large-scale impact and damage; and the disruption of infrastructure support necessary for the coordination of electricity, telecommunications, and transportation (Chen et al., 2008), but the problem is that coordination is often underestimated in emergency response studies even though it influences the loss of life and properties in affected areas (Chen et al., 2008).

While there are studies analyzing interorganizational coordination networks in emergency response management (Kapucu, 2005, 2009) there are few network analysis related studies looking at the network structure of individuals and groups. It seems no one has investigated the change of an organization's (node) position and role as it pertains to the network's dynamic transformation as the disaster is evolving and changing over time.

\subsection{Networks and Network Analysis}

Within the context of public administration and interorganizational theory, several definitions for network has been highlighted by Mandell and Steelman (2003). Kickert et al. (1997) focusing on the interdependency of networks, defined network as "[s]table patterns of social relations between interdependent actors which take shape around policy problems and/or policy programs" (p. 6). O'Toole (1997) defines networks as "structures of interdependence involving multiple organizations, or parts thereof, where one unit is not merely the formal subordinate of others in a larger superior-subordinate arrangement" (p. 45). They also cited Agranoff and McGuire's (1999) quote (p. 23) defining networks as 
"multi-actor structures designed to achieve a specific purpose and comprised of any number of organizational actors" Luke et al., 1988).

Considering the general terms of network in network science, a network is a set of individuals or groups, each of which has connections of some kind to some or all of the others. Networks operate on many levels and consist of many types, from a dyadic friendship or interactions among cells, to international cooperation networks. Networks play a critical role in determining the way problems are solved, organizations are run, markets evolve, and the degree to which individuals succeed in achieving their goals (Abbasi, Altmann, \& Hossain, 2011).

(Social) network analysis is a set of mathematical methods and tools used to analyze and visualize networks. In the language of network analysis, the people or groups are called 'actors' or 'nodes' and the connections 'ties' or 'links'. Both actors and ties can be defined in different ways depending on the questions of interest. An actor might be a single person, a team, or a company.

\subsection{Network Analysis Measures}

\section{Social Cohesion}

Social cohesion is often used to explain and develop sociological theories. Members of a cohesive subgroup tend to share information, have homogeneity of thought, identity, beliefs, behavior, even food habits and illnesses (Wasserman \& Faust, 1994). Social cohesion is also believed to influence emergence of consensus among group members (Balasundaram, et al, 2008). "Examples of cohesive subgroups include religious cults, terrorist cells, criminal gangs, military platoons, sports teams and conferences, and work groups etc" (Balasundaram et al., 2008).

Modeling a cohesive subgroup mathematically has long been the subject of interest in social network analysis. One of the earliest graph models used for studying cohesive subgroups was the clique model (Luce \& Perry, 1949). A clique is a sub graph in which there is a link between any two actors (vertices). However, the clique approach has been criticized for its overly restrictive nature (Alba, 1973; Wasserman \& Faust, 1994) and modeling disadvantages (Freeman, 1992; Seidman \& Foster, 1978). Clique models idealize three important structural properties that are expected of a cohesive subgroup, namely: familiarity (each node has many neighbors and only a few strangers in the group), reachability (a small diameter, facilitating fast communication between the group members) and robustness (high connectivity, making it difficult to destroy the group by removing members) (Balasundaram et al., 2008). 


\section{Network Density}

Density describes the general level of linkage among the actors in a network (Scott, 1991). The more points connected to one another, the denser the network is. So, the densest network is one in which all actors are connected with each other but such networks are very rare. In sum, density is "simply a measure of the extent to which all network organizations are interconnected, or linked to one another, and reflects network cohesiveness" (Provan \& Milward, 1995).

\section{The Giant Component}

In small networks, with few actors and connections, all individuals belong to a small group of collaboration or communication. As the total number of connections increases, however, there comes a point at which a giant component forms, this occurs when the largest number of nodes are all connected. It is important to realize that the response network can be fragmented in many clusters or can be fully connected. Fragmentation indicates that there is a pair of organizations that has no interaction with others at all.

\section{Connectivity}

A network is connected if each node can reach every other node. Thus, if at least two nodes are not directly connected, the network can be considered disconnected. The degree to which a network is disconnected is a function of the number of mutually disconnected pairs of nodes. As a result, dividing the number of pairs of disconnected nodes to all possible connections in a network (n(n-1)/2 where $\mathrm{n}$ is the number of nodes) gives the degree of a networks disconnectedness and consequently the degree of connectivity can be defined as the subtraction of that ratio from 1 (Krackhardt, 1994).

If the organizations are very separated from each other, then it is more difficult to organize them through a network (Krackhardt, 1994). During an incident involved individuals and organizations have many expectations from others (needs of information and resources). Thus, their connectivity is essential in responding to the emergency properly.

\section{Network Centralization}

A method used to understand networks and their participants is to evaluate the location of nodes in the network. Measuring the network location is about determining the centrality of its nodes. Node centrality measures help to determine the importance of a node in the network. Bavelas (1950) was the pioneer who initially investigated the formal properties of centrality and proposed 
several centrality concepts. Later, Freeman (1979) found that centrality has an important structural factor influencing leadership, satisfaction, and efficiency.

"The concepts of density and centralization refer to differing aspects of 'compactness' of a graph. Density describes the general level of cohesion in a graph; centralization describes the extent to which this cohesion is organized around particular focal points" (Scott, 1991). Degree centrality is an important node centrality measure. It is simply the number of other nodes connected directly to a node. Necessarily, a central node is not physically in the center of the network. The degree centrality of a node is calculated in terms of the number of its adjacent nodes.

To examine if a whole network has a centralized structure, one has to consider all node centrality measures. The general view is finding differences between the most central nodes' centrality scores and others'. Then, centralization is calculated as a ratio of the sum of these differences to the maximum possible sum of differences. A network centralization measure indicates how tightly the network is organized around its most central nodes. In sum, "centralization refers to the power and control structure of the network, or whether network links and activities are organized around any particular one or small group of organizations" (Provan \& Milward, 1995).

Bavelas (1948, 1950) and Leavitt (1951) applied the centrality concept as a surrogate for the position of actors in a network to investigate the relation between an actor's position and the coordination performance of the network. During their experiment (known as the MIT experiment) it was found that centralized structures (e.g., star or wheel networks) were far more conducive to performance (solving the puzzle faster) in contrast to decentralized or flatter structures (e.g., circle networks). The crux of the argument is that information flow is inefficient in decentralized networks and therefore less conducive to performance (Abbasi, Chung \& Hossain, in press). However, later research by Guetzkow and Simon (1955) revealed that decentralized structures actually worked better than centralized structures when tasks become more complex.

If a network's links are directed (the direction of the links between each two nodes is important), then we should use in-degree (considering the input links: links to a node) and out-degree (considering the output links: links from a node to others) centrality measures. Consequently, we will have network in- and outdegree centralizations.

\section{Contribution Index}

As in a directed network, it is usually easier to have a single measure rather than two (in- and out- degree), we use Gloor et al.'s (2003) proposed contribution index (CI) to combine out-degree (e.g., number of requests a node sends to 
others) and in-degree (e.g., number of requests a node receives from others). CI is defined for each node as below:

$$
C I(a)=\frac{\text { Out_degree }(a)-I n \_d e g r e e(a)}{\text { Out_degree }(a)+I n \_d e g r e e(a)}
$$

$\mathrm{CI}$ is +1 if the node only sends messages (out-degree $>0$ and in-degree $=0$ ). It is -1 if the node only receives messages (in-degree $>0$ and out-degree $=0$ ) and it is 0 if the node has a totally balanced communication behavior by sending and receiving the same number of messages (out-degree=in-degree).

\section{Data and Methodology}

\subsection{Data Collection}

In 2004, the state of Florida was struck by four consecutive major hurricanes within a six week period. Hurricane Charley occurred on August $13^{\text {th }}$. State officials estimated that more than 1.9 million people evacuated Florida during the 2004 hurricane season (FEMA 2005).

The data collected by Kapucu for four hurricanes in Florida in 2004 who conducted a content analysis by reviewing Florida State Emergency Response Team (SERT) situation reports before, during and after Hurricane Charley. SERT's situation reports were made available to the public daily and weekly, and outlined current response efforts being monitored through the State Emergency Operation Center (EOC). The data collection process numbered and catalogued organizations involved in response efforts. The transactions reported and focused on the response effort monitored by SERT situation reports.

\subsection{Methods}

Each issue was reviewed for articles that detailed community response to storm preparation, storm action, or post-storm responses. Each entry was numbered by date, the organizations were listed as separate entries and given organization numbers, the contact, sector, and source of funding were identified, and the transaction was recorded. Organizations that worked together and shared knowledge and resources to accomplish a task were noted (Kapucu et al., 2010).

From the result of the content analyzes of Hurricane Charley, the research team identified the main organizations involved in response and support management, in addition to other interactions amongst organizations. Thus, having actors (organizations) and links among them (their interactions) a picture of the interorganizational response network of Hurricane Charley was produced. 
UCINET (Borgatti, Everett, \& Freeman, 2002), a social network analysis software program was used to analyze the response network and its actors. Social network analysis measures the relations in a network and provides a comprehensive picture of the network relationship (Mandell \& Keast, 2007).

\section{Analyzes and ResultsInterorganizational Network Evolution}

During Hurricane Charley, 114 interactions among 96 distinct organizations between 08/12/2004 and 08/29/2004 were found, which provides the interorganizational cooperation (coordination) network produced to respond to the incident. In order to investigate dynamic changes and the emergence of the interorganizational response networks, we use five distinct time frames (durations), consisting of three days, except the last period (T5) which had very few interactions from August 24-29, all interactions of those five days were included in one duration.

Table 1 shows a distinct number of organizations (number of nodes) and the frequency of interorganizational interactions (number of links), network density, network connectedness, number of components, and their in- and out-degree network centralization measures for each duration in addition to the entire duration of Hurricane Charley.

Table 1. Hurricane Charley interorganizational response network statistics and measures over time

\begin{tabular}{l|c|c|c|c|c|r}
\hline & $\begin{array}{c}\text { T1 } \\
\text { Aug(12-14) }\end{array}$ & $\begin{array}{c}\text { T2 } \\
\text { Aug(15-17) }\end{array}$ & $\begin{array}{c}\text { T3 } \\
\text { Aug(18-20) }\end{array}$ & $\begin{array}{c}\text { T4 } \\
\text { Aug(21-23) }\end{array}$ & $\begin{array}{c}\text { T5 } \\
\text { Aug(24-29) }\end{array}$ & $\begin{array}{c}\text { All } \\
\text { Aug(12-29) }\end{array}$ \\
\hline \# of Organizations (nodes) & 34 & 28 & 25 & 24 & 17 & $\mathbf{9 6}$ \\
\# of Interactions (Links) & 30 & 28 & 19 & 24 & 13 & $\mathbf{1 1 4}$ \\
Density (\%) & 2.7 & 3.7 & 3.2 & 4.4 & 4.8 & $\mathbf{1 . 3}$ \\
Connectedness (\%) & 29.9 & 25.9 & 32.7 & 100 & 27.9 & $\mathbf{5 9 . 7}$ \\
\# of Components & 7 & 5 & 6 & 1 & 4 & $\mathbf{9}$ \\
Out-Degree Centralization (\%) & 3.5 & 5.1 & 14.1 & 34.1 & 41.5 & $\mathbf{4 . 9}$ \\
In-Degree Centralization (\%) & 31.6 & 5.1 & 27.1 & 11.3 & 14.9 & $\mathbf{3 . 2}$ \\
\hline
\end{tabular}

The results show that interorganizational response networks in all durations are very sparse (very low density). The first duration's (which includes the time the incident occurred) network has the most sparse structure, but the density of the response network structure does increase over time and reaches its densest in the last duration (T5) which is still very sparse.

The networks' low connectedness measures indicate that there are a lot of pairs of organizations that are not mutually reachable except at the fourth duration (T4) where there is at least one path between each pair of organizations in the network. Considering the entire duration, about $60 \%$ of organizations are connected to each other (can reach each other). Higher numbers of components indicates more 
unconnected sub-networks and, as results show, all the organizations are connected at T4 while in other cases there are several unconnected sub-networks.

In order to identify to what extent the networks are centralized (around one or few nodes), one must consider the number of links from each organization to their partners (i.e., out-degree). At T1 the network has the most decentralized structure but then changes toward a more centralized structure in the last durations. This reflects that at $\mathrm{T} 1$ many organizations are seeking resources but at T5 (and to some extent at T4 and T3) there are just a few organizations (at the center of the networks) which are seeking resources, as identified through many links to others.

On the other hand, considering the number of links to each organization from their partners (i.e., in-degree), results shows that at T1 the response network is more centralized around just a few organizations, providing support to others through receiving many requests (represented by links) from others.

Analyzing the network centralization of the entire duration and considering the organizations in-degree and out-degree centralization measures, a picture is painted in which the interorganizational response network structure is highly decentralized. This indicates that there is not a specific coordinating organization to manage and control requests and information flow. The response networks' structures are more centralized focusing on each period of time. This indicates that there are few organizations in the center of the network (not physically) communicating with other organizations at each duration.

\subsection{Organizations' Position Changes during Evolution of Response Network}

In order to investigate the dynamic changes of positions and roles of organizations during the evolution of the incident, we analyze the changes of the organizations' centrality measures (i.e., in-degree, out-degree) over time. Table 2 shows the top 20 provider organizations (having a high in-degree) which receive the most requests from other organizations that are seeking resources or any kind of support.

The first column shows the abbreviation of names and codes of the organizations in descending order of their overall normalized in-degree centrality measure (proportion of the number of links to the organization to all possible links of that organization) for the entire duration of the incident as shown in the second column. The following columns indicate the normalized in-degree measures and rank of the organization at each period. The blank fields indicate that the organizations did not receive any links (e.g., requests or information) at that duration.

As Table 2 shows, the organization SERT (\#333) has the highest in-degree centrality of the entire duration which means that it receives more links from others but not necessarily in every time period. As it is shown, it has no 
interaction (communication) at $\mathrm{T} 4$ and it was not ranked first in other durations. A similar situation applies to OCEM (\#333) and FEMA (\#2) as the second and the third highest central organizations. Interestingly, none of the organizations are active at all durations and there are just few organizations that are active providers (receiving links) at two or more durations.

Table 2. Top 20 provider organizations: organizations name (and code) ${ }^{1}$, in-degree centrality measure (and their order) over time

\begin{tabular}{|lcccccc|}
\hline Orgs. & All (T1-T5) & T1 & T2 & T3 & T4 & T5 \\
\hline SERT (333) & 3.37 & $24.2(2)$ & $6.2(1)$ & $8.3(2)$ & & $6.3(3)$ \\
OCEM (326) & 3.37 & $33.3(1)$ & $3.7(2)$ & $4.2(3)$ & $2.2(3)$ & \\
FEMA (2) & 3.16 & & $2.5(3)$ & $29.2(1)$ & $13.0(1)$ & \\
ARC (82) & 0.84 & & & & $2.2(3)$ & $18.8(1)$ \\
OCG (22) & 0.63 & & $1.2(4)$ & & $4.3(2)$ & \\
CityC (302) & 0.63 & $9.1(3)$ & & & & \\
FS (314) & 0.63 & $3.0(4)$ & $1.2(4)$ & $4.2(3)$ & & \\
WTFV (52) & 0.42 & & $2.5(3)$ & & & \\
OSG (87) & 0.42 & & $1.2(4)$ & & $2.2(3)$ & \\
SemC (332) & 0.42 & & $1.2(4)$ & & $2.2(3)$ & \\
DoAgr (304) & 0.42 & & $1.2(4)$ & & $2.2(3)$ & \\
PolkC (329) & 0.42 & & $1.2(4)$ & & $2.2(3)$ & \\
OEMO (327) & 0.42 & & $1.2(4)$ & & $4.3(2)$ & \\
FLNG (311) & 0.42 & & & & & $12.5(2)$ \\
Witt (344) & 0.42 & & & & $2.2(3)$ & \\
LakeC (322) & 0.42 & & $1.2(4)$ & & & \\
FSGO (1) & 0.21 & & & $4.2(3)$ & & \\
WKMG (51) & 0.21 & & $1.2(4)$ & & & \\
VoluCG (89) & 0.21 & & $1.2(4)$ & & & \\
\hline
\end{tabular}

On the other hand, Table 3 shows the top 20 seeker organizations which had more communications with other organizations (having high out-degree centrality measures) for seeking support. Although FDEM (\#13) is the most active seeker organization of the entire duration of the incident, it has no links to others at T1 and T3. It is the most central organization only during the last two durations. Again just a few organizations have links to others at two or more durations.

Comparing the two tables, we can see that only FEMA is among the top three seeker and provider organizations and SERT (as the top provider organization) is not in the list of seeker organizations, the same is found for FDEM (as the top seeker organization) which is not in the list of provider organizations. This

\footnotetext{
${ }^{1}$ The organizations full name including their abbreviation used in the text and code has been provided in the Appendix 1.
} 
indicates that they just send or receive requests and they are definitely not a good candidate to coordinate the interorganizational cooperative network. Obviously, the organizations which have both provider and seeker roles are the ones that are (somehow) coordinating the cooperation networks by passing the requests from seekers to providers.

Table 3. Top 20 seeker organizations: organizations name (and code), out-degree centrality measure (and their order) over time

\begin{tabular}{|lcccccc|}
\hline Orgs. & All (T1-T5) & T1 & T2 & T3 & T4 & T5 \\
\hline FDEM (13) & 5.05 & & $1.2(4)$ & & $34.8(1)$ & $43.8(1)$ \\
FEMA (2) & 1.47 & $6.1(1)$ & $4.9(2)$ & $4.2(3)$ & & \\
OCG (22) & 1.26 & & $4.9(2)$ & $4.2(3)$ & & $6.3(2)$ \\
PEF (63) & 1.05 & & $6.2(1)$ & & & \\
NHC (3) & 1.05 & $3.0(2)$ & $4.9(2)$ & & & \\
USG (72) & 1.05 & $3.0(2)$ & & $16.7(1)$ & & \\
CCEM (94) & 0.84 & & $4.9(2)$ & & & \\
OS (80) & 0.63 & $3.0(2)$ & & & $4.3(2)$ & \\
ARC (82) & 0.42 & & $2.5(3)$ & & & \\
WTFV (52) & 0.42 & $6.1(1)$ & & & & \\
FSGO (1) & 0.42 & & $2.5(3)$ & & & \\
HC (250) & 0.42 & $6.1(1)$ & & & & \\
ASST (54) & 0.42 & $6.1(1)$ & & & & \\
FIC (66) & 0.42 & $6.1(1)$ & & & & \\
HHS (105) & 0.42 & & & & & \\
AllSta(67) & 0.42 & $6.1(1)$ & & & & \\
PC (9) & 0.42 & $6.1(1)$ & & & & \\
OCSD (99) & 0.42 & & & & & \\
DCF (164) & 0.42 & & & $8.3(2)$ & & \\
\hline
\end{tabular}

In order to find these types of organizations, we use a contribution index which combines two measures (e.g., out- and in-degree centralities). In our dataset, we found just 8 organizations (out of 96) which have both links to and from other organizations (FEMA, OCG, ARC, WTFV, FSGO, OSG, WKMG, and VCG). On the other hand, to find active organizations (the ones connected to a higher number of organizations), we define average degree as the sum of the out-degree and in-degree divided by 2 . Thus, the highest average degree shows the most active organization, which is the one that has many connections or communications with more organizations regardless of direction of the connection.

Table 4 shows the top 20 active organizations in descending order of their average degree followed by their out- and in-degree centrality and contributionindex (CI). CI is 1 for the seeker organizations that have no providing role; -1 for 
the provider organizations that have no seeking role; and otherwise 0 for the organizations which are playing the role of coordinators through having both seeking and providing connections in the response network. FEMA is the most active organization which is linked both to and from other organizations (22 interactions). Thus, it is the best potential coordinator for the emergency response network.

Table 4. Top 20 active organizations: organizations name (and code), average degree, out-degree, indegree centralities and contribution-index (CI)

\begin{tabular}{|lcccc|}
\hline Org No. & Avg. Degree & Out- Degree & In- Degree & CI \\
\hline FDEM (13) & 12 & 24 & 0 & 1 \\
FEMA (2) & 11 & 7 & 15 & -0.36 \\
SERT (333) & 8 & 0 & 16 & -1 \\
OCEM (326) & 8 & 0 & 16 & -1 \\
OCG (22) & 4.5 & 6 & 3 & 0.33 \\
ARC (82) & 3 & 2 & 4 & -0.33 \\
PEF (63) & 2.5 & 5 & 0 & 1 \\
NHC (3) & 2.5 & 5 & 0 & 1 \\
USG (72) & 2.5 & 5 & 0 & 1 \\
CCEM (94) & 2 & 4 & 0 & 1 \\
WTFV (52) & 2 & 2 & 2 & 0 \\
OS (80) & 1.5 & 3 & 0 & 1 \\
FSGO (1) & 1.5 & 2 & 1 & 0.33 \\
OSG (87) & 1.5 & 1 & 2 & -0.33 \\
CityC (302) & 1.5 & 0 & 3 & -1 \\
FS (314) & 1.5 & 0 & 3 & -1 \\
HC (250) & 1 & 2 & 0 & 1 \\
ASST (54) & 1 & 2 & 0 & 1 \\
FIC (66) & 1 & 2 & 0 & 1 \\
\hline
\end{tabular}

\section{Discussions and Conclusion}

This paper investigates the dynamic changes of interorganizational response networks during response to Hurricane Charley (one of the major Hurricanes that hit Florida in 2004). The importance of network metrics was highlighted in order to analyze disasters response networks. The results show that there is no specific ordered trend for any of the interorganizational cooperative networks' measures which were explored in this study (i.e., density, connectedness, number of components, out-degree and in-degree centralizations) except for out-degree centralizations which increased over time. This implies that while immediately after the hurricane occurs, organizations involved in emergency response have an 
almost similar frequency of requests, but towards the end of the recovery process only a few organizations are seeking resources and information.

In order to investigate the evolving structure of the response network over time, this study splits the duration to smaller time frames (three days). The analysis shows that interorganizational response network structures are not fixed and vary in each period (depending on the circumstances). This study contributes to emergency management literature by considering and investigating the dynamic changes of organizational roles and positions throughout the evolution of interorganizational response networks during and following a national disaster.

Understanding the existing structure of networks is important to predict the nodes' local structure and positional change over time (Abbasi, Hossain \& Leydesdorff, 2012). Therefore, this study used network analysis measures in order to quantify and distinguish the response networks structure and each organization's position and structure in the response network for each time period. Using those measures, it was found that the rate of communication increases and creates conditions requiring organizational structures to move in a new direction to exchange new information which is usually away from their preparedness plans. This verifies the need for coordination by feedback as described by Dynes and Aguirre (1979). On the other hand, due to the complexity and dynamicity of coordination during disaster management, coordination by plan is of importance. Therefore, there is a need to combine both, coordination by plan and feedback, in order to move toward a more self-organize situation in which organizations cooperate collectively to respond efficiently to the disaster.

One of the criticisms to social network analysis is the lack of time dimension. Analyzes of networks are often times static and provide a snapshot of relationships. Thus, it would not be possible to capture a dynamic network picture. This study takes these criticisms into consideration and adds time dimension to the analysis of response networks. The response network was analyzed under five different time frames. As such, it is potentially a very useful contribution to the literature.

The study found that most of the central organizations (considering both information and resource seeker and provider organizations) over time were just requesting or providing and were not good candidates for coordinating the interorganizational response network which is needed to play the intermediating role of not only receiving requests from some organizations but also responding to them or forwarding their request to other proper organizations. Therefore, central or lead organizations are not necessarily the best potential coordinators.

In order to identify the real coordinators in the response network, this study used an average degree measure and the contribution-index. Average degree centrality is a surrogate for active organizations which have links to many other organizations. This variety of social ties helps them to become more familiar with 
each other and build trust among themselves. The contribution index is a proxy to distinguish the organizations that play two roles, as provider or seeker of resources.

The use of a single dataset can be considered one of the limitations of this study. In order to generalize results and findings, there is a need to apply these analyzes to more data points (and sources) in future studies. This approach is not only limited to disasters (natural, technological and manmade) management but can be applied in any other fields which coordination is needed.

\section{Appendix 1. Organozations' Code and Name}

\begin{tabular}{|c|c|c|}
\hline Org. Code & Org. Name & Org. Abbreviation \\
\hline 01 & Florida State Government - Governor's Office & FSG-GO \\
\hline 02 & Federal Emergency Management Agency & FEMA \\
\hline 03 & National Hurricane Center & $\mathrm{NHC}$ \\
\hline 13 & Florida Division of Emergency Management & FDoEM \\
\hline 22 & Orange County Government & OCG \\
\hline 52 & WFTV Channel 9 & WFTV-Channel9 \\
\hline 54 & A Sun State Trees & ASST \\
\hline 63 & Progress Energy Florida & PEF \\
\hline 66 & Florida Insurance Council & FIC \\
\hline 72 & United States Government & USG \\
\hline 80 & Orlando Sentinel & OS \\
\hline 82 & American Red Cross & $\mathrm{ARC}$ \\
\hline 87 & Osceola County Government & OCG \\
\hline 94 & Charlotte County Emergency management & CCEm \\
\hline 128 & Lake County Government & LCG \\
\hline 164 & Department of Children \& Families & DCF \\
\hline 250 & Hillsborough County & $\mathrm{HC}$ \\
\hline 326 & Orange County Government Emergency Management & OC EMO \\
\hline 333 & Florida State Emergency Response Team & SERT \\
\hline
\end{tabular}




\section{References}

Abbasi, A., Altmann, J., \& Hossain, L. 2011. Identifying the Effects of CoAuthorship Networks on the Performance of Scholars: A Correlation and $\underline{R}$ egression Analysis of Performance Measures and Social Network Ānalysis Measures. Journal of Informetrics, 5(4) : 594-607.

Abbasi, A., Chung, K. S. K., \& Hossain, L. 2012. Egocentric analysis of coauthorship network structure, position and performance. Information Processing \& Management, 48(4): 671-679.

Abbasi, A., Hossain, L., Hamra, J., \& Owen, C. 2010. Social Networks Perspective of Firefighters' Adaptive Behaviour and Coordination among Them. GREENCOM-CPSCOM 10 Proceedings of the 2010 IEEE/ACM Int '1 Conference on Green Computing and Communications \& Int'1 Conference on Cyber, Physical and Social Computing.

Abbasi, A., Hossain, L., \& Leydesdorff, L. 2012. Betweenness centrality as a driver of preferential attachment in the evolution of research collaboration networks. Journal of Informetrics, 6(3): 403-412.

Agranoff, R., \& McGuire, M. 1999. Managing Network Settings. Policy Studies Review, 16(1): 18-41.

Alba, R. D. 1973. A graph-theoretic definition of a sociometric clique. The Journal of Mathematical Sociology, 3(1): 113-126.

Balasundaram, B., Butenko, S., Hicks, I. V., \& Sachdeva, S. 2008. Clique relaxations in social network analysis: The maximum k-plex problem. Manuscript.

Bavelas, A. 1948. A mathematical model for group structures. Human organization, 7(3): 16-30.

Bavelas, A. 1950. Communication patterns in task-oriented groups. Journal of the Acoustical Society of America, 22: 725-730.

Borgatti, S., Everett, M., \& Freeman, L. 2002. Ucinet for windows: Software for social network analysis (version 6). Harvard, MA: Analytic Technologies.

Chen, R., Sharman, R., Rao, H., \& Upadhyaya, S. 2008. Coordination in emergency response management. Communications of the ACM, 51(5): 66-73.

Corbacioglu, S., \& Kapucu, N. 2006. Organisational Learning and Selfadaptation in Dynamic DisasterEnvironments. Disasters, 30(2): 212-233.

Crompton, R. P., \& McAneney, K. J. 2008. Normalised Australian insured losses from meteorological hazards: 1967-2006. Environmental Science \& Policy, 11(5): 371-378.

Drabek, T. E. 2006. Community Processes: Coordination. Handbook of Disaster Research: 217-233. 
Durland, M. M., \& Fredericks, K. A. 2002. Social Network Analysis in Program Evaluation: New Directions for Evaluation. San Francisco: Jossy-Bass.

Dynes, R. R., \& Aguirre, B. E. 1979. Organizational adaptation to crises: mechanisms of coordination and structural change. Disasters, 3(1): 71-74.

Freeman, L. C. 1979. Centrality in social networks conceptual clarification. Social Networks, 1(3): 215-239.

Freeman, L. C. 1992. The sociological concept of 'group': An empirical test of two models. American journal of sociology, 98(1): 152-166.

Gloor, P. A., Laubacher, R., Dynes, S. B. C., \& Zhao, Y. 2003. Visualization of communication patterns in collaborative innovation networks-analysis of some w3c working groups.

Guetzkow, H., \& Simon, H. 1955. The Impact of Certain Communication Nets upon Organization and Performance in Task-Öriented Groups. Management Science, 1(3/4): 233-250.

Hamra, J., Hossain, L., Owen, C., \& Abbasi, A. in press. Effects of Networks on Learning during Emergency Events. Disaster Prevention and Management.

Hossain, L., \& Kuti, M. 2010. Disaster response preparedness coordination through social networks. Disasters: 755-786.

Kapucu, N. 2005. Interorganizational coordination in dynamic context: Networks in emergency response management. Connections, 26(2): 33-48.

Kapucu, N. 2006. Interagency communication networks during emergencies: Boundary spanners in multi-agency coordination. The American Review of Public Administration, 36(2): 207.

Kapucu, N. 2009. Interorganizational Coordination in Complex Environments of Disasters: The Evolution of Intergovernmental Disaster Response Systems. Journal of Homeland Security and Emergency Management, 6(1): Article 47.

Kapucu, N. 2012. The Network governance in response to acts of terrorism: Comparative analyses. New York, NY: Taylor and Francis.

Kapucu, N., Bryer, T., Garayev, V., \& Arslan, T. 2010. Interorganizational Network Coordination under Stress Caused by Repeated Threats of Disasters. Journal of Homeland Security and Emergency Management, 7(1): 45.

Kapucu, N., \& Ozerdem, A. 2011. Managing emergencies and crises. Boston, MA: Jones \& Bartlett Publishers.

Kickert, W. J. M., Klijn, E.-H., \& Koppenjan, J. F. M. 1997. Introduction: A Management Perspective on Policy Networks. In W. J. M. Kickert, E.-H. Klijn, \& J. F. M. Koppenjan (Eds.), Managing Complex Networks: Strategies for the Public Sector. London: Sage Publications. 
Kilduff, M., \& Tsai, W. 2003. Social networks and organizations: Sage Publications Ltd.

Krackhardt, D. 1994. Graph theoretical dimensions of informal organizations. Computational organization theory: 89-111.

Leavitt, H. J. 1951. Some effects of certain communication patterns on group performance. The Journal of Abnormal and Social Psychology, 46(1): 3850 .

Luce, R. D., \& Perry, A. D. 1949. A method of matrix analysis of group structure. Psychometrika, 14(2): 95-116.

Luke, J. S., Ventriss, C., Reed, B. J., \& Reed, C. M. 1988. Managing economic development. San Francisco, CA: Jossey-Bass.

Malone, T. W. 1988. What is coordination theory? Paper presented at the MIT Sloan School of Management, Working Paper No.2051-88.

Malone, T. W., \& Crowston, K. 1990. What is coordination theory and how can it help design cooperative work systems?

Malone, T. W., \& Crowston, K. 1994. The interdisciplinary study of coordination. ACM Computing Surveys (CSUR), 26(1): 87-119.

Mandell, M., \& Keast, R. 2007. Evaluating network arrangements: Toward revised performance measures. Public Performance \& Management Review, 30(4): 574-597.

Mandell, M., \& Steelman, T. 2003. Understanding what can be accomplished through interorganizational innovations The importance of typologies, context and management strategies. Public Management Review, 5(2): 197-224.

McEntire, D. A. 2002. Coordinating multi-organisational responses to disaster: lessons from the March 28, 2000, Fort Worth tornado. Disaster Prevention and Management, 11(5): 369-379.

Moynihan, D. P. 2005. Leveraging collaborative networks in infrequent emergency situations: IBM Center for the Business of Government.

Moynihan, D. P. 2006. What makes hierarchical networks succeed? Evidence from hurricane Katrina.

Munich Re Group. 2005. Annual review: natural catastrophes 2004.

O’Toole Jr, L. J. 1997. Treating networks seriously: Practical and research-based agendas in public administration. Public Administration Review, 57(1): 45-52.

Provan, K. G., \& Milward, H. B. 1995. A preliminary theory of interorganizational network effectiveness: A comparative study of four community mental health systems. Administrative Science Quarterly, 40(1): 1-33. 
Provan, K. G., Veazie, M. A., Staten, L. K., \& Teufel Shone, N. I. 2005. The use of network analysis to strengthen community partnerships. Public Administration Review, 65(5): 603-613.

Scott, J. 1991. Social network analysis: a handbook.: Sage.

Seidman, S. B., \& Foster, B. L. 1978. A graph-theoretic generalization of the clique concept. The Journal of Mathematical Sociology, 6(1): 139-154.

Swiss Reinsurance Company. 2006. Natural catastrophes and man-made disasters 2005: high earthquake casualties, new dimension in windstorm losses., Vol. Sigma No. 2, Zurich.

Uzzi, B. S. 1994. Organizationanle tworks, structurael mbeddedness, and firm survival., national meeting of the Academy of Management. Dallas, TX.

Van Borkulo, E., Scholten, H., Zllatanova, S., \& van den Brink, A. 2005. Decision making in response and relief phases.

Varda, D. M., Forgette, R., Banks, D., \& Contractor, N. 2009. Social network Methodology in the study of disasters: Issues and insights prompted by post-Katrina research. Population Research and Policy Review, 28(1): 1129.

Wasserman, S., \& Faust, K. 1994. Social network analysis: Methods and applications: Cambridge Univ Press. 